\title{
End of Life Papers
}

\section{Permanent vegetative state: comparing the law and ethics of two tragic cases from Italy and England}

\author{
Paquita de Zulueta \\ Honorary Senior Clinical Lecturer, Imperial College, London, UK \\ Francesco Carelli \\ Professor, Elective Courses Family Medicine, University of Milan, Italy
}

\section{Introduction}

In April 1989, in England, Tony Bland aged 17 was trampled and crushed by a stampede at the Hillsborough football stadium ground - a disaster in which 95 people were killed. His lungs were crushed and punctured and the supply of oxygen to his brain was temporarily interrupted. Nearly three years later, in January 1992, in Italy, Eluana Englaro aged 21 lost control of her father's car whilst driving at night on an icy road and crashed into a lamp post, fracturing her skull and neck. When these young people were admitted to hospital, both of them were found to have suffered devastating anoxic brain damage and both were later diagnosed as being in a persistent vegetative state. Their illness narratives have several commonalities, but they also diverge in significant ways. In this article we shall be exploring the views of the relatives, the public, and the health professionals, how their voices were heard, and how the values underpinning these differing accounts were interpreted by the courts of law. We shall critically evaluate the ethical and legal justifications for the final decision to allow these unfortunate young people to die from the withdrawal of nutrition and hydration. We shall also consider the influence and interventions of the Church and the State in these two countries and how the law in England and in Italy resolved the moral and legal issues. From this analysis we shall reflect on what would appear to be the most humane and reasonable way forward.

\section{Definition}

The term persistent vegetative state was first coined by Jennett and Plum to describe a specific syndrome of brain-damaged patients who can breathe spontaneously, have a stable circulation, retain reflex activity and a normal sleep-wake pattern, but are unable to respond meaningfully to their environment. ${ }^{1}$ Persistent vegetative state is now a term usually applied to the condition if it lasts between one month and one year and is distinguished from permanent vegetative state (PVS) when the condition has lasted for more than one year, as with the above. A working party of the Royal College of Physicians provide a detailed guidance in 2003 for the diagnosis and management of PVS. $^{2}$

The term 'vegetative' carries the unfortunate association in the lay mind of 'vegetable-like', but, despite efforts to change it, the name has endured. ${ }^{3}$ In practical terms, with good care, an individual in PVS can live several decades and is therefore not terminally ill. Philosophically this condition challenges everyday concepts and of what it means to be human and to be alive. It creates conflicts regarding the notions of human dignity and personal identity. These individuals can be viewed as existing in a kind of limbo, a grey zone, with no interest in whether they live or die no sense of self or others and no meaningful way of communicating with the outside world. For those who knew and loved them, to bear witness to seeing these individuals lying there, insensate, their bodies changing with the passage of time and to be unable to communicate with them, is an emotionally painful, even shocking, experience. 


\section{The narratives}

After more than three years, Tony Bland's family and his medical team applied via the hospital trust to seek declarations from the High Court to allow the lawful discontinuation of life-sustaining treatments, including artificial nutrition and hydration (ANH). When giving evidence, the family could not recall any time that Tony had expressed his wishes should he find himself in his current condition. His father was of the firm opinion that his son would 'certainly not want to be left like he is' and that he could see 'no point whatsoever in continuing treatment'. The declarations were granted, and were later upheld by the highest court in the land, the House of Lords, in February 1993. ${ }^{4}$ Tony Bland died in early March 1993 after nine days of withdrawal of food and water, and just under four years since his original injury. The public reaction was relatively muted, albeit there was considerable discourse in the lay, religious and academic press. Religious leaders made their voices heard but this did not result in any political intervention.

In the case of Eluana, on the other hand, her doctors did not remove her feeding tubes until February 2009, 17 years after her accident, and amidst a strident and emotional debate within her country. Her father, Beppino Englaro, had fought for this decision for over a decade, angering the Catholic Church and senior politicians in doing so. He claimed that Eluana specifically brought up the subject a year before her accident when a friend of hers had a motorbike accident and suffered severe brain damage. She had told her father that she would prefer to die and not be resuscitated if she were in such a state. ${ }^{5}$ Her friends and cousin also gave testimony that in her situation she would wish to be allowed to die. The Appeals Court in Milan decided that Eluana's condition was irreversible and that the deciding factor should be the patient's own expressed wishes prior to the incapacity, as recalled by her family and friends. Finally in November 2008 Englaro won the support of the highest court of the land: The Court of Cassation decreed that feeding could be stopped. ${ }^{6}$ But, unlike the case in the UK after the House of Lords ruling, the legal process did not stop there. Various religious organisations and a Human Rights group sought to have the court's ruling annulled by the European Court of Human Rights, but they were unsuccessful.

The Vatican's spokesman, Cardinal Javier Lozano Barragán described the withdrawal of ANH as a 'monstrous and inhuman murder'. The Church took the view that this was euthanasia (illegal in Italy, as it is in the UK) by the back door. The minister for welfare, Maurzio Sacconi, 'following his conscience', stepped in and threatened financial ruin or 'unimaginable consequences' to any clinic that acquiesced with the judicial ruling. Subsequently doctors from a private clinic offered help, as all the other state-funded institutions were intimidated into refusing, even though several senior doctors expressed sympathy for $\mathrm{Mr}$ Englaro. The Prime minister, Silvio Berlusconi, heavily leant on by the Vatican, also attempted to intervene with a ministerial decree barring doctors from stopping nutrition - effectively overruling the court's decision. The head of state, President Giorgio Napolitano, however, refused to sign the decree, declaring it as unconstitutional. Sacconi still continued to seek legal loopholes to declare the private clinic's activity as illegal, and Berlusconi threatened to push legislation through parliament that would compel doctors to keep her alive. But these attempts failed, and Eluana died three days after her doctors began a medical protocol of gradual withdrawal of nutrition and hydration with sedation. Despite a vocal minority, results of a poll suggested that the great majority of Italians felt this was the proper way for her to be allowed to die. In typical sensationalistic language, Berlusconi claimed that she had been 'killed'.

\section{The legal framework and issues}

\section{Medical treatment}

The first crucial issue under consideration was whether ANH consisted of medical treatment or normal nursing care, for if ANH constituted normal care, then discontinuation would not be permissible. Both the UK and Italian courts accepted the transatlantic legal precedent ${ }^{7}$ where ANH was defined as medical treatment. This is still a highly contested point and it is noteworthy that the Royal College of Nursing took the opposing view in Bland. The Schiavo case, regarding a woman with PVS in the USA, also raised considerable controversy and has distinct parallels with the Englaro case. $^{8,9}$

\section{Duty of care, criminal liability and murder: Italy}

Both Italian and English courts considered that criminal liability would exist if life-sustaining treatment were deliberately withheld from a patient towards whom there was a duty of care. In Italy the pivotal tests for delineating the duty were, firstly, that the condition was irreversible such that Eluana would never regain consciousness and be able to express her wishes directly, and secondly that her father and close others were truly and unequivocally representing her voice, her personal beliefs, and her way of thinking prior to falling into a state of unconsciousness i.e. her 
'substituted judgement'. More specifically, there had to be an assurance that she had made a clear request to decline treatment should she be in this state. If so, it was permissible to withhold or withdraw treatment, and indeed there was a duty to accede to her will. It was made clear that this would not represent euthanasia (a criminal offence), that is to say deliberately ending her life, but rather an acceptance of the patient's rejection of treatment, thereby allowing the disease to take its course. Arguably Italian jurisprudence managed to find a balanced and reasonable way to enable people's wishes to be respected at the end of life.

\section{UK law: acts and omissions}

The situation in England was more complex as nobody could confirm Tony Bland's prior autonomous wishes. The key issues revolved around the concept of sanctity of life, the scope of the duty of care, and the evaluation of best interests. Despite acknowledging the lack of a clear logical or ethical rationale for making a distinction between actively bringing about death by a lethal drug (commission) and the withholding of treatment (omission), the Lords endorsed it, declaring active killing to be unlawful for reasons of policy: 'For once euthanasia is recognised as lawful in these circumstances, it is difficult to see any logical basis for excluding it in others'. ${ }^{10}$ McCall Smith argues that this distinction in criminal law is necessary as it maintains psychological realism and prevents the creation of unreasonable expectations regarding people's moral obligations. He further argues that this distinction expresses a widespread moral intuition and there is every reason for according such intuitions a central role in our morality. ${ }^{11}$ This is a valid point, but not one that everyone will agree with.

\section{UK: standard and duty of care}

The law lords in the UK made specific reference to the Bolam standard of care whereby a respectable body of medical opinion provides the standard for what constitutes reasonable treatment. ${ }^{12}$ Aside Bolam, Lord Mustill pointed out that discontinuation of treatment was ethically justified as the continuation of treatment could no longer serve to maintain his personality and that it was not in Bland's best interests 'for he has no best interests of any kind'. ${ }^{13}$ Lord Browne-Wilkinson judged that the doctor cannot owe the patient a duty of care when life can only be sustained by 'intrusive medical care' that the patient could not consent to. He further argued that if treatment was not in the best interests of the patient, it was unlawful to continue with it and constituted the crime of battery. Since there was no duty to maintain life, the doctor could not be guilty of murder by omission.

\section{Sanctity of life}

This was upheld in all the courts from both countries as a fundamental concept, underpinned by the deeply held view that human life has an intrinsic value, irrespective of whether one holds religious or nonreligious beliefs. But, as Lord Hoffman stated, this view represents 'a cluster of ethical principles which we apply to decisions about how we live'. ${ }^{14} \mathrm{He}$, and the other English law lords emphasised that it also involves respecting the right to self-determination and human dignity, and that sanctity of life was not absolute. Indeed, if taken to extreme, by maintaining life at all costs, it could be cruel, invasive and burdensome.

\section{Quality of life and best interests}

It was agreed from the medical evidence that Tony Bland was not capable of suffering and therefore there was no question of alleviating his suffering or of causing suffering by withdrawal of food and nutrition. But since Tony Bland was indifferent to whether he lived or died, arguably there was nothing to put in the balance against the intrinsic value of his life. Lord Hoffman attempted to rebut this argument by providing a substituted judgement, claiming that Bland in his present state would have chosen to die rather than to live. He also took the view that it was more respectful of Tony Bland's dignity and memory to allow him to die rather than to keep him 'grotesquely alive'. ${ }^{15}$ Lord Browne-Wilkinson was even more extreme and described Bland's condition as a 'living death'. ${ }^{16}$ The Lords all agreed that it was not in his interests to be kept alive, and that treatment would not lead to an amelioration of his condition, and was therefore futile. The 'recovery argument', however, is weakened by the fact that treatment for disabled people is not necessarily to effectuate a recovery, but may also be to slow down deterioration or maintain existing functioning. ${ }^{17}$

\section{Self-determination}

Ironically, despite all the obstacles that Englaro encountered, it transpires that the Italian law, as it currently stands, appears to allow more flexibility in its determination of a patient's prior wishes. In the UK, the Mental Capacity Act (2005) creates a framework whereby people can determine how they are treated in the future should they lose capacity. ${ }^{18}$ The withdrawal of treatment in a case of PVS would require the authorisation of the Court of Protection. An advance decision ( $\mathrm{AD}$, 'living will') would have to have been made by an adult (Bland was still a minor when he had his accident) at a time when he/she had capacity to refuse future treatment. An AD can be oral 
or written, but must specify the treatment options in clear unambiguous language. In the case of refusal of life-saving treatment, it must be in writing, signed by the person and witnessed. The treatment refused must be specified. Eluana's father could be seen to have acted as a proxy decision maker, but again the requirements in the UK would be more stringent and she would have had to have appointed him as her lasting power of attorney (LPA). An LPA includes health and welfare decisions but does not extend to the refusal of life-saving treatment, unless specifically stated. The LPA has to be registered with the Office of the Public Guardian. ${ }^{19}$ In fact, one cannot help wondering if the bureaucracy and formality involved has not paradoxically created more barriers for individuals.

\section{The role of the state, the Church and the law}

In summary, we have two young people disastrously brain damaged and incapacitated provoking a painful and public debate regarding their future. In both cases the families wished treatment to end and were supported by the law and, in the case of the UK, the medical profession (but not the nursing profession). In Italy, the medical professional was divided and Italy appeared to be in danger of sliding into a constitutional mayhem and theocracy. The religious stance, however, is relatively new (since 2004, when Pope John Paul delivered a papal allocution on the subject) and the Catholic tradition in fact offers two competing viewpoints on the ethics of withdrawing or withholding ANH. ${ }^{20}$ The idea of a UK minister threatening the profession defies belief, and there would be a public outcry if the prime minister acted under the instigation of a religious leader. Fortunately there remained a clear-headed head of state capable of showing integrity and sound judgment. This case highlights the need for an independent judiciary capable of settling complex ethical and legal decisions without political intervention. Euthanasia cannot be considered in isolation from the broader law of homicide, and the debate has to involve the law, although judges do not have any special expertise in making difficult value judgments, as Lord Mustill openly acknowledged in Bland. At the time of writing, the Italian Senate approved a draconian bill that would disallow the withdrawal of ANH in any circumstance and would render the implementation of advance directives near impossible. Whether the bill is approved by all of parliament and made law is still in the balance.

\section{Conclusion}

Debates about euthanasia reveal the different visions of what constitutes the 'good life' and what it is to be human. The increasing secularisation of British society has not led so far to the legalisation of voluntary or involuntary euthanasia, despite the greater emphasis on individual autonomy. Conversely, in Italy, where the Catholic Church occupies a more influential position, the law enshrines the doctrine of selfdetermination, but in practice this is hard to implement. In both cases some kind of legal compromise was reached: in Italy there was an acceptance that an individual's prior wishes are determinative, even though arguably that person no longer exists, and in England a subjective quality of life assessment was made that permitted treatment to be discontinued in the full knowledge that death would follow. Both decisions aimed to reflect a compassionate and holistic view of what it means to be fully human.

\section{ACKNOWLEDGEMENTS}

The authors wish to thank Tana de Zulueta for her clarification of the Italian political and legal processes.

\section{CONFLICTS OF INTEREST}

None.

\section{REFERENCES}

1 Jennett B and Plum F. Persistent vegetative state after brain damage. Lancet 1992;1:734-7.

2 Royal College of Physicians. The Vegetative State. Guidance on Diagnosis and Management. Report of a Working Party of the Royal College of Physicians. London: RCP, 2003.

3 Andrews K. Vegetative state - background and ethics. JR Soc Med 1997;90:593-6.

4 Airdale NHS Trust $v$ Bland [1993] 1 All ER 821.2 WLR 316. H.L.(E).

5 Day M. A father's plea: let my daughter die in peace. The Observer, 8 February 2009. Available at: www.guardian. co.uk/world/2009/feb/08/eluana-englaro-assisted-suicide.

6 For a translated summary of the Court's ruling see www. istitutobioetica.org Fusco M. Sentenza Englaro.

7 Re Conroy (1985) 486 A. 2d. 1209: Cruzan v Director, Missouri Department of Health (1990) 110S. Ct 2841.

8 Quill TE. Terri Schiavo - a tragedy compounded NEJM 2005; 352:1630-3.

9 Annas GJ. 'Culture of Life' Politics at the bedside - the case of Terri Schiavo. NEJM 2005; 352:1710-15.

10 Airdale NHS Trust v Bland [1993] per Lord Goff, 369.

11 McCall Smith A. Euthanasia: the strengths of the middle ground. Med Law Review 1999;7:194-207.

12 Bolam v Friern HMC [1957] 2 All ER 118. 
13 Airdale NHS Trust v Bland [1993] per Lord Mustill, 398.

14 Airdale NHS Trust v Bland [1993] per Lord Hoffman, 351.

15 Airdale NHS Trust v Bland [1993] per Lord Hoffman, 354.

16 Airdale NHS Trust v Bland [1993] per BrowneWilkinson, 381

17 Andrews K. Recovery of patients after four months or more in the persistent vegetative state. BMJ 1993;306: 1597-1600.

18 www.dca.gov.uk/menincap/legis.htm

19 For the LPA regulations see www.opsi.gov.uk/si/si2007/ uksi_20071253_en_1.
20 Fine RL. From Quinlan to Schiavo: medical, ethical and legal issues in severe brain injury. Baylor Medical Center Proceedings 2005;18(4):303-10.

\section{ADDRESS FOR CORRESPONDENCE}

Paquita de Zulueta

27a Lansdowne Crescent

London W11 2NS

UK

Email: p.dezulueta@imperial.ac.uk 